\title{
PEMANFAATAN LIMBAH KULIT JAGUNG DAN AMPAS TEBU SEBAGAI KERTAS KEMASAN RAMAH LINGKUNGAN
}

\author{
UTILIZATION OF CORN AND BAGGASE SKIN WASTE \\ AS A PACKAGING PAPER ENVIRONMENTALLY FRIENDLY
}

\author{
Oktaffi Arinna Manasikana*, Andhika Mayasari, Noer Af'idah \\ Universitas Hasyim Asy'ari \\ J1. Irian Jaya No.55 Tebuireng Jombang 61471 \\ *e-mail korespondensi: changemakersalatiga@gmail.com
}

\begin{abstract}
Abstrak
Adanya peningkatan besar akan kebutuhan kertas dan keinginan masyarakat dengan teknologi ramah lingkungan terus meningkat, menyebabkan pemasokan bahan baku kertas besar pada sektor industri kertas. Keterbatasan pemasokan bahan baku produksi kertas karena faktor isu lingkungan menyebabkan naiknya harga kertas. Kandungan ampas tebu yaitu selulosa, pentosan, lignin dan lainlain, sedangkan komposisi kulit jagung adalah selulosa, hemiselulosa abu, dan lignin. Komponenkomponen tersebut dapat dijadikan sebagai bahan pembuatan kertas karena memiliki kandungan selulosa tinggi. Diharapkan kertas yang dihasilkan dapat digunakan sebagai bahan kemasan ramah lingkungan. Tujuan dari penelitian ini yaitu mengetahui potensi limbah kulit jagung dan ampas tebu sebagai bahan pembuatan kertas kemasan ramah lingkungan, serta menganalisis perbandingan antara komposisi kulit jagung dan ampas tebu untuk menghasilkan kertas kemasan dengan mutu terbaik. Metode yang digunakan eksperimen dengan Rancangan Acak Lengkap (RAL) menggunakan tiga sampel dan dua kali ulangan. Uji sampel pada penelitian ini meliputi uji tarik, elastisitas dan biodegradabilitas. Hasil penelitian menunjukkan bahwa limbah kulit jagung dan ampas tebu berpotensi sebagai kertas kemasan ramah lingkungan. Kertas dengan mutu terbaik yaitu pada perbandngan $25 \%$ kulit jagung dan $75 \%$ ampas tebu dengan uji tarik sebesar 14,8 $\mathrm{N}$ uji elastisitas $13,33 \%$ dan luas kertas terbiodegradasi $50 \%$.
\end{abstract}

Kata kunci: limbah, kulit jagung, ampas tebu, kertas kemasan

\begin{abstract}
The increasing need for paper and the demands of the community for environmentally friendly technology is increasing, causing the need for a large supply of paper raw materials to the paper industry sector. The limited supply of raw materials for paper production caused by environmental issues causes the price of paper to rise. The content of bagasse is cellulose, pentosan, lignin and others, while the content of corn husk consists of ash, lignin, cellulose, and hemicellulose. These components can be used as paper making materials because they have high cellulose content. The resulting paper is expected to be used as an environmentally friendly packaging material. The purpose of this study is to determine the potential of corn husk waste and bagasse as an environmentally friendly packaging paper material, as well as to analyze the comparison between the composition of corn husk and sugarcane bagasse to produce the highest quality packaging paper . The test samples used in this study are tensile, elasticity and biodegradability tests. The results showed that corn husk waste and sugarcane bagasse have the potential to be environmentally friendly packaging paper. Paper with the best quality is compared to $25 \%$ corn husk and $75 \%$ bagasse with a tensile test of $14.8 \mathrm{~N}$ elasticity test of $13.33 \%$ and $50 \%$ biodegrated paper area.
\end{abstract}

Keywords: waste, corn husk, bagasse, paper packaging 


\section{PENDAHULUAN}

Di Indonesia kebutuhan kertas mengalami peningkatan. Kebutuhan kertas yang meningkat sebanding dengan keinginan masyarakat memiliki teknologi ramah lingkungan, sehingga dibutuhkannya yang besar pula bahan baku sektor industri kertas. Untuk itu, diperlukan lebih banyak bahan baku serat dalam pembuatan kertas. Bahan baku serat yang dipakai dalam pembuatan kertas yaitu kayu. Penggunaan kayu yang terus meningkat ini akan mengakibatkan sumber daya kayu akan semakin menipis.

Indonesia merupakan penghasil utama tanaman jagung dan tebu namun hasil limbah tanaman tersebut belum termanfaatkan secara maksimal. Kurangnya ketersediaan bahan baku kayu karena produksi kertas disebabkan adanya isu lingkungan menyebabkan harga kertas naik. Untuk mengatasi hal tersebut, maka alternatif nya harus ada bahan baku pengganti kayu sebagai penghasil kertas. Untuk mendukung pemerintah mengatasi penyediaan kertas dalam negeri dan mengurangi ketergantungan bahan baku kayu, maka mengganti bahan baku, yaitu dengan material non kayu (non-wood fiber) dan termauk sebagai serat alam, spesifiknya dari material tumbuhan (vegetable fibres) yaitu salah satunya adalah ampas tebu dan kulit jagung.

Menyadari pentingnya kelestarian lingkungan dan keberlanjutan kehidupan manusia, telah berkembang paradigma tentang konsep perancangan yang ramah terhadap lingkungan dan saat ini menjadi paradigma pengembangan berkelanjutan. Rekayasa hijau mengevaluasi proses manufaktur sebagai suatu sistem dan berusaha mengoptimalkan desain (dan dalam arti arti sebenarnya) menggabungkan konsep analisis siklus hidup dan ekonomi lingkungan secara keseluruhan. Diharapkan dengan adanya kesadaran akan paradigma baru ini maka kelestarian lingkungan hidup dan keberlanjutan kehidupan manusia akan senantiasa terjaga. (Tilaar,dkk, 2011).

Klobot jagung atau kulit jagung adalah bagian paling luar dari jagung untuk melindungi bagian dalam jagung. Kulit jagung adalah lembaran serat modifikasi sebagai pelindung tongkol jagung. Struktur morfologi klobot atau kulit jagung memiliki permukaan yang kasar dan berwarna hijau muda sampai hijau tua. Komposisi kulit jagung terdapat pada Tabel 1.

Ampas tebu (baggase) komposisi kimia terbesar adalah ligno-cellulose. Ligno-cellulose mempunyai panjang 1,7 hingga $2 \mathrm{~mm}$ dan diameter 20 mikro, karakter ini menyebabkan ampas tebu dapat dimanfaatkan sebagai papanpapan buatan (Purnawan,dkk, 2013). Ampas tebu (baggase) mengandung komposisi gula $3,3 \%$, serat rata-rata $47,7 \%$ dan air $48-52 \%$. Serat ampas tebu tidak bisa larut dalam air dan komposisi terbesar adalah lignin, selulosa, dan pentosan (Husin, 2007). Hasil uji analisis serat bagas terdapat pada Tabel 2. Dari bahan kering, ampas tebu terdiri unsur C (carbon) 47\%, O (oxygen) 44\%, abu (Ash) 2,5\% dan $\mathrm{H}$ (Hydrogen) 6,5\%.

Tabel 1. Komposisi Kulit Jagung

\begin{tabular}{lc}
\hline \multicolumn{1}{c}{ komposisi } & $\%$ \\
\hline Lignin & 9,6 \\
Alcohol-cyclohexane solubility $(1: 2 \mathrm{v} / \mathrm{v})$ & 41 \\
Ash & 1,5 \\
Cellulose & 36 \\
\hline
\end{tabular}

(Sumber: Anjani, 2014)

Tabel 2. Komposisi Ampas Tebu

\begin{tabular}{lc}
\hline Kandungan & Kadar $(\%)$ \\
\hline Abu & 3,82 \\
Sari & 1,81 \\
$\mathrm{SiO} 2$ & 3,01 \\
Selulosa & 37,65 \\
Pentosan & 27,97 \\
Lignin & 22,09 \\
\hline
\end{tabular}

(Purnawan, dkk, 2013).

Kertas kemasan ramah lingkungan bila ditinjau aspek penggunaan bahan baku,proses produksi, pengiriman atau distribusi, pemakaian hemat energi, pembuangan ke lingkungan bisa di-recycle dan mempunyai tingkat biodegradabilitas tinggi. Kertas kemasan dari limbah kulit dan tongkol jagung diharapkan menjadi kemasan ramah lingkungan karena penggunaan bahan baku alami dari limbah alam organik dan proses pembuangan mempunyai tingkat biodegradabilitas tinggi.

Kesadaran akan pemanfaataan limbah kulit jagung dan ampas tebu untuk melakukan suatu pengelolaan lingkungan menghasilkan kertas kemasan ramah lingkungan. Kulit jagung dan ampas tebu dapat dimanfaatkan sebagai bahan pembuatan kertas, karena mempunyai kandungan selulosa tinggi. Untuk menguji mutu terbaik kertas maka dilakukan uji tarik, uji elastisitas dan uji biodegradabiitas. 
Jurnal Zarah, Vol. 7 No. 2 (2019) |81

\section{METODE PENELITIAN}

Bahan pada penelitian ini kulit jagung, ampas tebu, kertas bekas, lem $\mathrm{pVaC}$, kanji dan air. Alat penelitian pada pembuatan kertas adalah blender, alat pencetak kertas, pisau, gunting, alat untuk merebus, saringan, ember kotak, dan meja landasan. Penelitian ini dilaksanakan di Laboratorium IPA dan Teknik Mesin FIP Unhasy Tebuireng Jombang.

Metode yang digunakan eksperimen Rancangan Acak Lengkap (RAL) tiga sampel dua kali ulangan. (1) Sampel pertama perbandingan 50\% kulit jagung : 50\% ampas tebu; (2) sampel kedua 75\% kulit jagung : $25 \%$ ampas tebu dan (3) sampel ketiga 25\% kulit jagung : 75\% ampas tebu. Pengujian mutu kertas kemasan dengan uji tarik, elastisitas dan biodegradabilitas.

Proses pembuatan kertas diawali dengan pengeringan kemudian penggilingan kulit jagung dan ampas tebu. Pengeringan berfungsi untuk mengurangi kadar air. Penggilingan berfungsi untuk menjadikan kulit jagung dan ampas tebu sebagai serbuk agar mempermudah proses selanjutnya dan membuat kertas kemasan yag dihasilkan bertekstur halus. Proses selanjutnya adalah pemasakan hingga mendidih dengn penambahan tepung kanji dan lem pVAC sebagai perekat kertas agar lebih kuat kemudian dicetak dengan pencetak kertas dan dijemur langsung sinar matahari.

Kertas kemudian dilakukan uji tarik dan uji elastisitas di Laboratorium Teknologi Pertanian Universitas Brawijaya. Uji biodegradabilitas dilakukan dengan metode soil burial test yaitu memanfaatkan media tanah yang digunakan sebagai medium untuk pengamatan pengurangan masa (biodegradable) dari sampel, parameter yang diukur adalah besar pengurangan massa dari sampel setelah ditimbun dalam medium tanah selama waktu tertentu. Pengamatan dilakukan selama 4 minggu, dimana setiap minggu ditimbang besar pengurangan massanya. Sebelum dilakukan uji biodegradable sebelumnya sudah dipersiapkan medium tanah yang telah dikondisikan dengan menambahkan EM4. Diagram alir penelitian dapat terlihat Gambar 1.

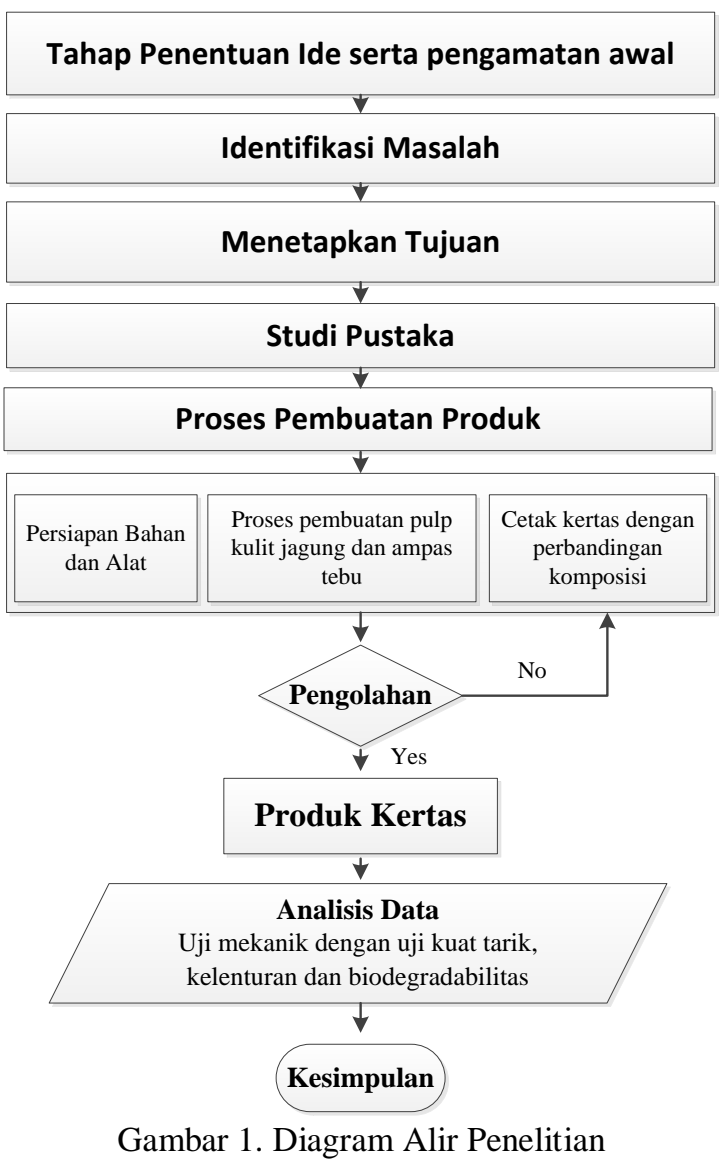

\section{HASIL DAN PEMBAHASAN}

Hasil penelitian dari pemanfaatan kulit jagung dan ampas tebu sebagai bahan pembuatan kertas kemasan ramah lingkungan bertujuan untuk mengetahui potensi kertas dari kulit jagung dan ampas tebu sebagai bahan baku alternative kertas kemasan ramah lingkungan dan menganalisis perbandingan antara komposisi kuit jagung dan ampas tebu untuk menghasilkan kertas kemasan dengan mutu terbaik. Kertas hasil penelitian dapat dilihat pada Gambar 2.

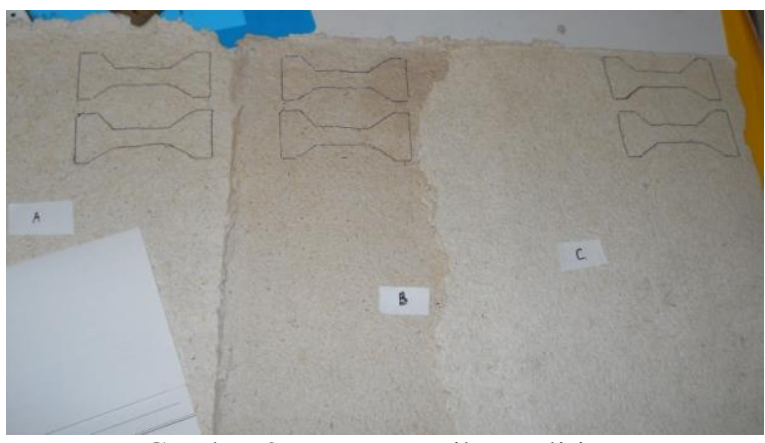

Gambar 2. Kertas Hasil Penelitian 
82 | Jurnal Zarah, Vol. 7 No. 2 (2019)

Pada Gambar 2 terlihat warna kertas abu-abu muda hal ini karena dipengaruhi oleh bahan kertas dari serbuk kulit jagung dan ampas tebu. Pada pengujian ini adalah untuk mengetahui pengaruh variasi ampas tebu dan kulit jagung sebagai bahan dasar pembuatan kertas. Sifatsifat fisik yang dianalisa meliputi tensile strength (MPa), elongation (\%) dan sifat biodegrabilitas. Persiapan awal sebelum dilakukan pengujian kuat tarik (tensile trength) dan pemanjangan (elongation) dilakukan dengan memotong benda uji dengan pola seperti yang terlihat pada Gambar 3. Pengujian tensile strength dan elongation pada kertas yang dihasilkan ini dilakukan dengan menggunakan Instron Universal Testing Machine. Mesin yang digunakan pengujian ini dapat dilihat pada Gambar 4.

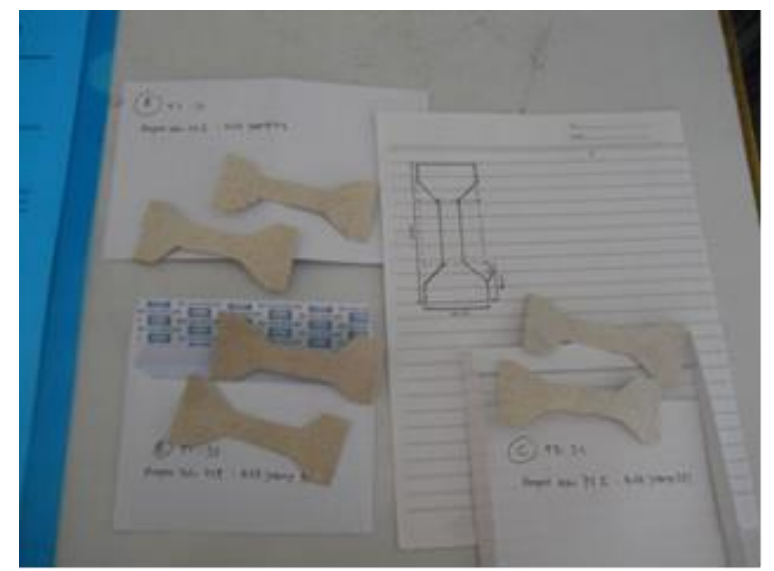

Gambar 3. Persiapan awal sebelum pengujian tensile strength

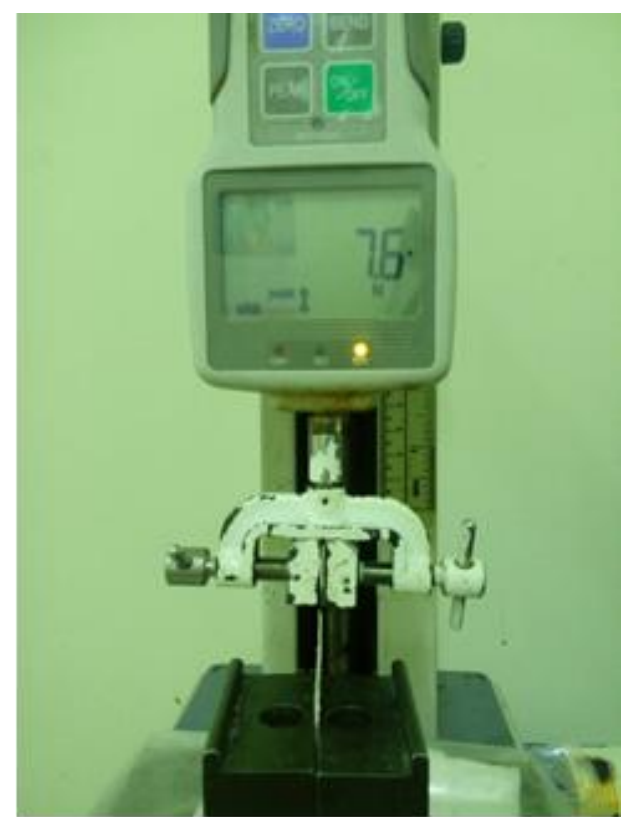

Gambar 4. Proses pengujian tensile strength dan elongation

\section{Uji Kuat Tarik Kertas}

Kekuatan renggang putus (tensile strength) merupakan gaya tarik maksimal yang hingga kertas bertahan tidak sobek atau putus (Prasetyawati, 2015). Pengukuran tensile strength berguna untuk mengetahui gaya tarik maksimal kertas persatuan luas saat direnggangkan. Data hasil uji tarik kertas dapat dilihat pada Tabel 3 dan diagram uji tarik kertas dari limbah kulit jagung dan ampas tebu terlihat pada Gambar 5.

Tabel 3. Data hasil uji tarik kertas

\begin{tabular}{cccc}
\hline Uji & Kode & $\begin{array}{c}\text { Kuat Tarik } \\
(\mathrm{N})\end{array}$ & Keterangan Kode \\
\hline 1 & A.J1 : T1 & 5,8 & $50 \%$ jagung : 50\% tebu \\
2 & A.J1 : T1 & 7,6 & $50 \%$ jagung : 50\% tebu \\
3 & B.J3 : T1 & 4,5 & $75 \%$ jagung : 25\% tebu \\
4 & B.J3: T1 & 6,8 & $75 \%$ jagung: $25 \%$ tebu \\
5 & C.J1 : T3 & 12,4 & $25 \%$ jagung : $75 \%$ tebu \\
6 & C.J1 : T3 & 14,8 & $25 \%$ jagung : $75 \%$ tebu \\
\hline
\end{tabular}

\section{Grafik Uji Tarik Kertas}

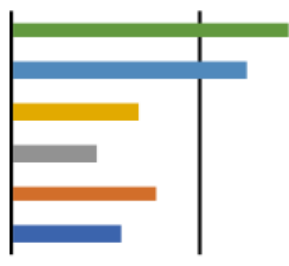

$\square \mathrm{U} 1 / \ldots$

Gambar 5. Diagram uji tarik kertas dari limbah kulit jagung dan ampas tebu

Hasil Gambar 5 dari uji tarik kertas dari limbah kulit jagung dan ampas tebu menunjukkan bahwa kertas yang memiliki kekuatan uji tarik tertinggi adalah pada U6/CJ1:T3 yaitu pada sampel dengan perbandingan $25 \%$ kulit jagung dan $75 \%$ ampas tebu dengan kuat tarik 14,8 N.

Kuat tarik adalah sebuah lembaran kertas terp tarikan di kedua ujungnya dalam kondisi standar (SII-0436-81). Banyaknya serbuk ampas tebu lebih banyak dari kulit jagung akan menghasilkan kertas kemasan yang mempunyai kuat tarik tinggi, dan kulit jagung yang lebih sedikit dari ampas tebu akan didapatkan kertas kemasan yang mempunyai rendah kuat tariknya.

Penyebabnya diantaranya komposisi selulosa pada ampas tebu lebih tinggi daripada kulit jagung. Anjani, 2014 menyebutkan bahwa kulit jagung kering mengandung selulosa $36 \%$. 
Komposisi kimia dari ampas tebu mengandung selulosa $37,65 \%$. Penggilingan pulp berpengaruh pada kuat tarik kertas, disebabkan pencampuran pulp berpengaruh pada pencampuran tepung kanji dan lem PVAc pada pulp. Tepung kanji dan lem PVAc berfungsi menyatukan dan merekatkan ikatan pada serat. Pencampuran lem PVAc yang merata dalam pulp akan membuat ikatan antar serat semakin baik.

Hal yang berpengaruh pada gaya tarik kertas diantaranya komposisi selulosa dan homegenitas perekat yang dipakai. Beberapa faktor lain yang mempengaruhi yaitu :

1. Panjang serat

Serat lebih panjang mempunyai gaya tarik lebih tinggi daripada serat yang lebih pendek.

2. Ikatan antar serat

Pendidihan dalam proses pulping bermanfaatan untuk pelarutan lignin sehingga serat akan cepat halus. Serat yang hancur akan mudah membentuk ikatan serat satu dengan yang lain. Semakin banyak serat yang berikatan maka ketahanan tariknya akan semakin tinggi.

3. Persentase selulosa

Sifat ketahanan tarik dipengaruhi oleh jumlah selulosa yang terdapat pada lembaran kertas. Hal tersebut didukung oleh pernyataan Mulyana (2007) bahwa bahan dengan komposisi selulosa sedikit akan memiliki ketahanan tarik yang lebih rendah dan sebaliknya komposisi kimia dengan selulosa yang tinggi akan mempunyai kuat tarik tinggi.

4. Homogenitas perekat

Ikatan antar serat akan diisi oleh perekat. Perekat harus homogen sehingga kertas kuat dan tidak robek.

Tabel 4. Data hasil uji elastisitas kertas

\begin{tabular}{|c|c|c|c|}
\hline No & Kode & $\begin{array}{c}\text { Elastisitas } \\
(\%)\end{array}$ & Keterangan Kode \\
\hline 1 & U1/ AJ1 : T1 & 6,67 & $50 \%$ jagung : $50 \%$ tebu \\
\hline 2 & $\mathrm{U} 2 / \mathrm{AJ} 1: \mathrm{T} 1$ & 10,00 & $50 \%$ jagung : $50 \%$ tebu \\
\hline 3 & $\mathrm{U} 3 / \mathrm{BJ} 3: \mathrm{T} 1$ & 6,67 & $75 \%$ jagung : $25 \%$ tebu \\
\hline 4 & U4/ BJ3: T1 & 10,00 & $75 \%$ jagung: $25 \%$ tebu \\
\hline 5 & U5/ CJ1 : T3 & 13,33 & $25 \%$ jagung : $75 \%$ tebu \\
\hline 6 & U6/ CJ1 : T3 & 13,33 & $25 \%$ jagung : $75 \%$ tebu \\
\hline
\end{tabular}

\section{Uji Elastisitas Kertas}

Pemanjangan (elongation) didefinisikan sebagai prosentase perubahan panjang kertas, pada saat kertas ditarik sampai putus (Prasetyawati, 2015). Hasil dari pengaruh variasi ampas tebu dan kulit jagung terhadap elastisitas dapat dilihat pada Gambar 6.

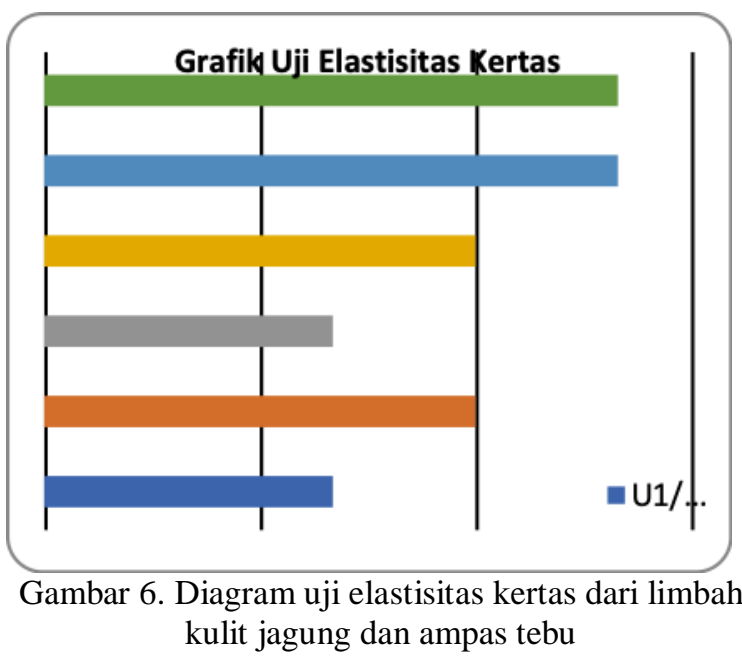

Hasil Gambar 6 dari uji elastisitas kertas dari limbah kulit jagung dan ampas tebu menunjukkan bahwa kertas yang memiliki kekuatan uji elastisitas tertinggi adalah pada U6/CJ1:T3 yaitu pada sampel dengan perbandingan $25 \%$ kulit jagung : $75 \%$ ampas tebu dengan kuat elastisitas 13,33\%. Elastisitas (elongation) adalah prosentase perubahan panjang kertas, pada saat kertas ditarik sampai putus sehingga sampel dengan hasil uji tarik tertinggi akan memiliki elastisitas tertinggi. Terdapat beberapa faktor yang mempengaruhi elastisitas dintaranya:

1. Ketebalan kertas

Ketebalan kertas dipengaruhi oleh proses pengepresan atau penekanan struktur permukaan kertas saat pencetakan. Apabila proses pengepresan dilakukan secara manual akan sangat mungkin ketebalan kertas tidak sama sehinggga kemampuan elastisitas kertas akan berbeda.

2. Waktu penggilingan atau blender.

Penggilingan pulp berfungsi untuk meratakan perekat serta memperhalus pulp. Pulp yang digiling dengan waktu yang lebih lama akan menghasilkan pulp yang lebih halus dan juga perekat lebih homogen. Semakin pulp dan perekat tergiling secara homogen, maka ikatan antar serat semakin tinggi, sehingga ketahanan elastisitas kertas semakin tinggi.

3. Homogenitas perekat

Perekat berfungsi untuk memperkuat ikatan antar serat kertas dari kulit jagung dan ampas tebu. Adanya perekat menyebabkan lembaran kertas menjadi lebih kuat dan tidak mudah putus ketika kedua ujung kertas ditarik. Lem PVAc yang tercampur secara homogen akan mengisi ruang antar serat sehingga 
84 | Jurnal Zarah, Vol. 7 No. 2 (2019)

memperkuat ikatan antar serat dan ketahanan tariknya tinggi sehingga elastisitasnya tinggi.

4. Panjang serat

Panjang serat yang terbentuk pada saat pulping akan mempengaruhi ikatan antar serat. Akibat proses penggilingan,masingmasing perlakuan memiliki panjang serat yang berbeda-beda. Kertas dengan serat yang pendek memiliki daya ikat yang lebih tinggi dari pada serat yang panjang, sehingga serat yang pendek memiliki ketahanan tarik yang lebih tinggi dan elastisitas yang tinggi daripada serat yang panjang.

Hal yang berpengaruh pada elastisitas yaitu kemampuan serat dalam mengikat, pressing, pulping yang mempengaruhi morfologi kertas. Serat pada lembaran pulp mempunyai daya gabung tinggi. Pada material dengan hemiselulosa rendah maka pulping akan sukar digiling dan menghasilkan lembaran berkekuatan rendah, salah satunya karena.

\section{Uji biodegradabilitas kertas}

Proses biodegradabilitas berfungsi untuk mengetahui kemampuan kertas untuk terurai oleh mikrobactanah. Hal ini berkaitan dengan sifat fisik tanah seperti suhu, kelembapan dan sifat lainnya.

Uji biodegradabilitas dilakukan dengan medium tanah karena mewakili salah satu kondisi lingkungan dimana biasanya limbah plastik dibuang. Uji Biodegradable dilakukan secara in-vitro yaitu dilakukan dalam tempat tertutup yang telah dikondisikan sebagai medium untuk membantu berkembangnya mikroba yang akan membantu proses uji biodegradable. Data hasil uji biodegradabilitas dapat dilihat pada Tabel 3 dan diagram uji biodegradabilitas kertas dari limbah kulit jagung dan ampas tebu terlihat pada Gambar 7.

Tabel 5. Data hasil uji biodegradabilitas

\begin{tabular}{|c|c|c|c|c|c|}
\hline \multirow[t]{2}{*}{ Uji } & \multirow[t]{2}{*}{ Kode } & \multicolumn{3}{|c|}{ Pan jang $(\mathrm{cm})$} & \multirow{2}{*}{$\begin{array}{l}\text { Keterangan } \\
\text { Kode }\end{array}$} \\
\hline & & Mg 1 & $\operatorname{Mg} 2$ & $\mathrm{Mg} 3$ & \\
\hline 1 & $\begin{array}{l}\text { A.J1: } \\
\text { T1 }\end{array}$ & $9,1 \times 8,3$ & $7,9 \times 6,8$ & $5,8 \times 5,9$ & $\begin{array}{c}50 \% \text { jagung : } \\
50 \% \text { tebu }\end{array}$ \\
\hline 2 & $\begin{array}{l}\text { A.J1: } \\
\text { T1 }\end{array}$ & $9,2 \times 8,0$ & $8,2 \times 7,5$ & $6,2 \times 5,7$ & $\begin{array}{c}50 \% \text { jagung : } \\
50 \% \text { tebu }\end{array}$ \\
\hline 3 & $\begin{array}{l}\text { B.J3 : } \\
\text { T1 }\end{array}$ & $8,9 \times 8,7$ & $6,9 \times 6,8$ & $5,3 \times 5,5$ & $\begin{array}{c}75 \% \text { jagung : } \\
25 \% \text { tebu }\end{array}$ \\
\hline 4 & $\begin{array}{l}\text { B.J3: } \\
\text { T1 }\end{array}$ & $9,3 \times 8,5$ & $7,5 \times 6,7$ & $6,1 \times 5,3$ & $\begin{array}{c}75 \% \text { jagung: } \\
25 \% \text { tebu }\end{array}$ \\
\hline 5 & $\begin{array}{l}\text { C.J1 : } \\
\text { T3 }\end{array}$ & $8,8 \times 8,2$ & $6,2 \times 6,4$ & $5,1 \times 4,9$ & $\begin{array}{c}25 \% \text { jagung : } \\
75 \% \text { tebu }\end{array}$ \\
\hline 6 & $\begin{array}{l}\text { C.J1 : } \\
\text { T3 }\end{array}$ & $9,4 \times 8,0$ & $8,0 \times 6,9$ & $6,1 \times 4,8$ & $\begin{array}{c}25 \% \text { jagung : } \\
75 \% \text { tebu }\end{array}$ \\
\hline
\end{tabular}

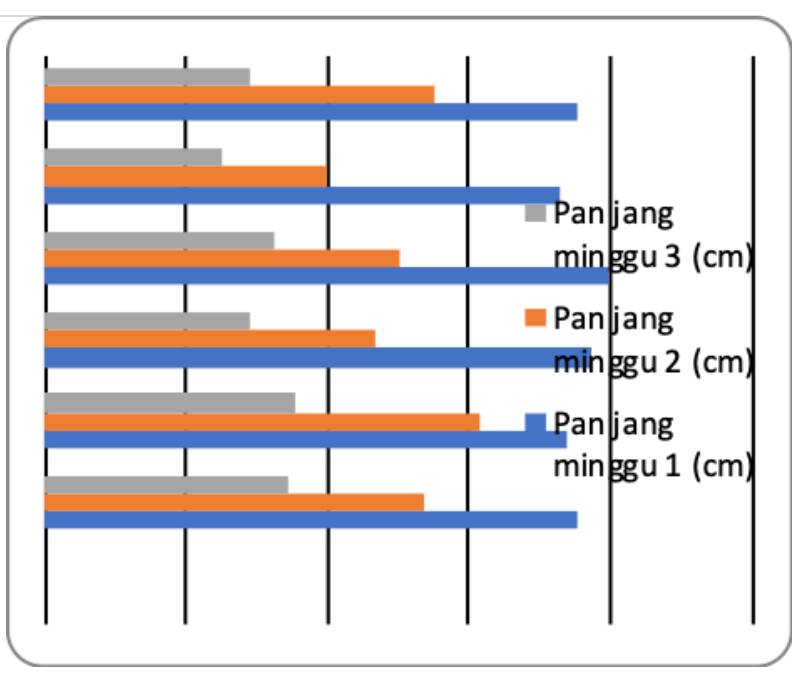

Gambar 7. Diagram uji biodegradabilitas kertas dari limbah kulit jagung dan ampas tebu

Pada Gambar 7 menunjukkan banyaknya panjang yang terdegradasi meningkat dengan lamanya waktu penimbunan komposit. Secara umum penurunan panjang berlangsung secara linier dengan waktu. Hal ini kemungkinan disebabkan kondisi lingkungan yang tidak homogen tiap minggu seperti keadaan suhu dan kelembaban yang berubah.

Larutan EM4 dapat mempengaruhi proses degradasi dari suatu sampel, karena makin banyak mikroorganisme dalam suatu wadah akan mempercepat proses penguraian. Hal ini sesuai dengan penelitian dimana smua sampel dapat terbiodegradasi dengan meningkat setiap pekannya. Dengan menghitung luas awal kertas sebelum dan sesudah kertas terdegradasi. Diperoleh rerata dari prosentase proses degradasi kertas kemasan dari limbah kulit jagung dan ampas tebu adalah 58\%. Pada penelitian Maytana, 2016 proses degradasi kertas dipengaruhi oleh bahan perekat kertas. Sampel dengan uji biodegrdabilitas tercepat adalah sampel U5/ CJ1:T3 yaitu pada sampel dengan perbandingan $25 \%$ kulit jagung dan 75 $\%$ ampas tebu dengan luas terdegradasi $50 \%$. Hal ini disebabkan sampel dengan ampas tebu lebih banyak mempunyai kandungan selulosa yang tinggi sehingga kuat tarik dan presentase elastisitasnya tinggi ini yang menyebabkan proses biodegradasinya juga tinggi artinya semakin mudah terdegradasi.

\section{KESIMPULAN}

Limbah kulit jagung dan ampas tebu berpotensi sebagai kertas kemasan ramah lingkungan. Kertas dengan mutu terbaik yaitu pada perbandngan $25 \%$ kulit jagung dan $75 \%$ ampas tebu dengan uji tarik sebesar $14,8 \mathrm{~N}$ uji 
elastisitas $13,33 \%$ dan luas kertas terbiodegradasi $50 \%$. Hasil penelitian ini dapat digunakan sebagai masukan bagi industri kertas bahwa limbah kulit jagung dan ampas tebu yang biasanya terbuang dapat dimanfaatkan sebagai bahan baku kertas kemasan ramah lingkungan.

\section{DAFTAR RUJUKAN}

Anjani,.W.,E. (2014), Pemanfaatan Tongkol Jagung Sebagai Bahan Baku Pembuatan Pulp Dengan Metode Soda, Jurusan Teknik Kimia, Politeknik Negeri Sriwijaya.

Cinantya,. P. (2015). Ekstraksi Asam Oksalat Dari Tongkol Jagung Dengan Pelarut HNO3, Tugas Akhir, Program Studi Teknik Kimia, Fakultas Teknik, Universitas Negeri Semarang.

Hasdiana. (2016).Laporan penelitian Model Rancangan Produk Kriya Tekstil Aplikatif dengan Memanfaatkan Limbah Kulit Jagung. Universitas Negeri Gorontalo

Tilaar, M., Wong,. L., W., Anna,. S., R. (2011). Pioneers In Green Science. Jakarta: Dian Rakyat

Mayasari A., Pranoto Y., Sarto. (2013). Pembuatan Edible Film Berbahan Dasar Limbah Kulit Singkong Dengan Penambahan Gliserol dan Kitosan Sebagai Pengemas Bumbu Mie Instan, Tesis, Universitas Gadjah Mada, Yogyakarta
Maytana,. R. (2017). Investigasi Sifat Biodegradasi dari Kemasan Kertas Berbasis Komposit Ramah Lingkungan dari campuran kanji dann pVac, Universitas Negeri Sebelas Maret.

Ningsih,. E, R. (2012). Uji Kinerja Digester Pada Proses Pulping Kulit Jagung Dengan Variabel Suhu dan Waktu Pemasakan, Tugas Akhir, Program Diploma, Fakultas Teknik, Universitas Diponegoro, Semarang.

Prasetyawati,. D., P. (2015), Pemanfaatan Kulit Jagung dan Tongkol Jagung (Zea mays) Sebagai Bahan Dasar Pembuatan Kertas Seni Dengan Penambahan Natrium Hidroksida $(\mathrm{NaOH})$ dan Pewarna Alami, Naskah Publikasi, Program Studi Pendidikan Biologi, Fakultas Keguruan dan Ilmu Pendidikan, Universitas Muhammadiyah Surakarta.

Purnawan C., Hilmiyana D., Wantini, Fatmawati E. (2013). Pemanfaatan Limbah Ampas Tebu Untuk Pembuatan Kertas Dekorasi Dengan Metode Organosolv, Jurnal EKOSAINS, Vol. IV No.2, Universitas Sebelas Maret, Surakarta.

Vitaloka,. A,. Rohanah,. A,. Rindang,. A. (2017). Karakteristik Kertas Berbahan Baku Ampas Tebu dan Sampah Kertas, Keteknikan Pertanian, Jurnal Rekayasa Pangan dan Pertanian, Vol.5 No.1, Fakultas Pertanian USU Medan. 